\title{
Erratum to: Technological Innovations for High-Throughput Approaches to In Vitro Allergy Diagnosis
}

\author{
Martin D. Chapman ${ }^{1}$ - Sabina Wuenschmann ${ }^{1}$ • Eva King ${ }^{1}$ • Anna Pomés ${ }^{1}$
}

Published online: 30 July 2015

(C) Springer Science+Business Media New York 2015

Erratum to: Curr Allergy Asthma Rep (2015) 15: 36

DOI 10.1007/s11882-015-0539-8

In the original version of this article the Conflict of Interest statement contains a mistake. The correct statement should have read as follows:

Conflict of Interest Martin D. Chapman declares that he is a founder and co-owner of Indoor Biotechnologies. Sabina Wuenschmann, Eva King, and Anna Pomés declare that they are employees of Indoor Biotechnologies.

The online version of the original article can be found at http://dx.doi.org/ $10.1007 / \mathrm{s} 11882-015-0539-8$.

\footnotetext{
Martin D. Chapman

mdc@inbio.com

1 Indoor Biotechnologies, Inc., 1216 Harris Street,

Charlottesville, VA 22903, USA
} 